\title{
Trends of Caesarean Delivery in a Tertiary Care Hospital in North Karnataka
}

\author{
Sridevi H. Satish ${ }^{1}$, Suyash Gandi ${ }^{2}$, Aruna M. Biradar ${ }^{3}$, Sangamesh S. Mathapati ${ }^{4}$, Sinigdha Snehi ${ }^{5}$ \\ 1, 2,3,4,5 Department of OBG, BLDE (Deemed to Be University), \\ Shri B.M. Patil Medical College, Vijayapura, Karnataka, India.
}

\section{ABSTRACT}

\section{BACKGROUND}

The drastically increasing rate of Caesarean section (CS) is a topic of constant worry and analysis throughout the world. In order to understand the degree to which Caesarean section may be preventable, it is important to know why Caesarean sections are performed. Due to nonexistence of any standard classification for indications of Caesarean section, indications for the same vary among institutions. We wanted to evaluate the rates and predictors of Caesarean section among institutional deliveries in a tertiary care hospital in an economically backward rural area.

\section{METHODS}

This was a cross-sectional prospective study. Pregnant women who underwent Caesarean section (CS) between June 2019 and December 2019 at BLDE (DU) Shri. B. M. Patil Medical College Hospital and Research Centre, Vijayapur, Karnataka, were recruited for the study. Demographic and obstetric data including indications of Caesarean section and pregnancy outcomes were collected and analysed.

\section{RESULTS}

The mean age of the study participants was $24.62+/-3.77$ years. The study patients were multigravidas, majority delivered at term. The mean gestational age was 38.09 + / - 2.023. The common indications were previous CS (33.1\%), cephalopelvic disproportion (16.9\%), hypertensive disorders of pregnancy (6.7\%) and maternal request (3.4\%). Post-delivery, majority of the babies (78.92\%) were stable and were on mother's side.

\section{CONCLUSIONS}

Previous caesarean section is the leading cause of Caesarean section in modern era. Hence reduction in primary caesarean section can reduce the rate of over all Caesarean section rate. Clinical, judgmental skills of the obstetrician, legal issues and the patient demands all contribute in the increasing trends of Caesarean section. Hence proper training, obstetric audit, and counselling of the patient party helps in changing the trends of increasing caesarean rate.

\section{KEY WORDS}

Caesarean Section, Indications for Caesarean Section, Maternal Morbidity
Corresponding Author: Dr. Aruna M. Biradar, Department of $O B G$, BLDE (Deemed to Be University), Shri B.M. Patil Medical College, Vijayapura, Karnataka, India. E-mail: aruna.biradar@bldedu.ac.in

DOI: $10.14260 /$ jemds $/ 2021 / 278$

How to Cite This Article:

Satish SH, Gandi S, Biradar AM, et al. Trends of Caesarean delivery in a tertiary care hospital in north Karnataka. J Evolution Med Dent Sci 2021;10(18):1319-1323, DOI: 10.14260/jemds/2021/278

Submission 30-12-2020, Peer Review 04-03-2021, Acceptance 10-03-2021, Published 03-05-2021.

Copyright (C) 2021 Sridevi H. Satish et al. This is an open access article distributed under Creative Commons Attribution License [Attribution 4.0 International (CC BY 4.0)] 


\section{BACKGROUND}

In today's era, delivery by caesarean section has become the 'new normal'. Caesarean section is a surgical procedure involving incision of the walls of the abdomen and uterus for delivery of offspring. This term should never be applied to the removal of a child from the abdomen after rupture of the uterus and to any procedure of abdominal pregnancy. Indeed, it is the most commonly performed obstetrical procedure throughout the world. Normal vaginal delivery has lost its normality because of various issues like more pain and suffering to the mother, risk of injury to the baby, fear of litigation to the doctor etc. In contrast Caesarean section is painless, elective and involves much less risk for both to the mother and foetus. The World Health Organization (WHO) suggested a Caesarean section rate of $10-15 \%$ as the upper limit for any country at the population level. ${ }^{1}$ Many of them have raised above this recommendation and some have exceeded it by a wide margin. ${ }^{2}$ However, infant and mortality rates don't seem to show a proportionate decrease in most parts of the world. ${ }^{3}$ According to The Federation of Obstetric and Gynaecological Societies of India, individualization of predilection for the women in labour with the expectation of a successful and safe vaginal delivery is the hallmark of labour management in this century, in cahoots with the ability to intervene with a caesarean section, if needed, to prevent morbidity and mortality4. It was perceived that higher caesarean section rates were associated with lower maternal and infant mortality only up to a specific point, after which Caesarean section rates were not significantly associated with these positive outcomes.5,6 Approximately 4-fold increase in the risk of maternal mortality is associated with Caesarean delivery. Maternal saturninity rates are larger Caesarean surgeries than vaginal deliveries. The causes of the maternal morbidity are endometritis, myometritis, postpartum haemorrhage (PPH), urinary tract infections and thromboembolism. Obese patients have much higher morbidity. In addition, unnecessary Caesarean deliveries are associated with higher health care costs in many low-income settings. In the last decade in India the rates of Caesarean section have almost magnified from $9.0 \%$ in 2008 to $18.7 \%$ in 2018 among institutional births and in private set up the percentages peaks to almost $40-45 \%{ }^{7}$ When we look into the causes for this steep increase, non-medical indication like preference of dates, economic affluence ${ }^{5}$ etc. On the other hand post-operative maternal morbidity occurs in $9-15 \%$ of Caesarean sections and it lowers fertility rates as compared to vaginal birth. ${ }^{8}$ In neonates the risk of respiratory morbidities increases in cases of elective Caesarean section. ${ }^{9}$ Many studies have observed that the neonates born through $\mathrm{C}$-section have low bacterial exposure, which in turn changes their immunity and gut microbiome diversity. Children are expected to have high chances of allergy, asthma, and childhood obesity. The increasing trend of rates may indicate a trend towards a more costly medical delivery systems and lowered threshold of abnormality detection among the health care providers. In India, Janani Suraksha Yojana and maternal ambulances services in rural areas which was started in last decade have brought many significant changes in maternal and perinatal outcomes in India, due to which there is significantly raised number of institutional deliveries, this may have brought a difference in pattern of Caesarean sections as well, analysis of which has not been incorporated in much of the studies. If above mentioned factors can be clarified, it may indicate specific areas that could be targeted to control Caesarean section rates. It is time to realize that c sections not only put both the mother and child at risk, but also have huge economic burden compared to normal vaginal delivery. Thus, the current study is planned to understand the rates and indications of Caesarean section among institutional deliveries in a tertiary care hospital in an economically backward rural area.

\section{METHODS}

A prospective cross-sectional study was conducted at BLDE (DU) Shri. B. M. Patil Medical College Hospital and Research Centre, Vijayapur, Karnataka from June 2019 to December 2019 after obtaining the institutional ethical committee clearance. A total of 670 beneficiaries who underwent caesarean section for delivering their babies were included in the study. The purpose of the study was explained using informed consent document and such consent was obtained from each of the study subjects. For the purpose of the study, complete history of the study participants including their age, previous history of pregnancy, previous mode of delivery and indication of caesarean section elective or emergency was noted. The gender and status of the child after birth was also noted.

\section{Statistical Analysis}

Statistical analysis was done using summary statistics of Mean \pm SD, Freeman-Halter Fisher test. Data were analysed by SPSS v.23.0 and Microsoft office 2007.

\section{RESULTS}

The study participants were predominantly young belonging to the age group of 21 - 25 years followed by 26 - 30 years as shown in Figure 1.

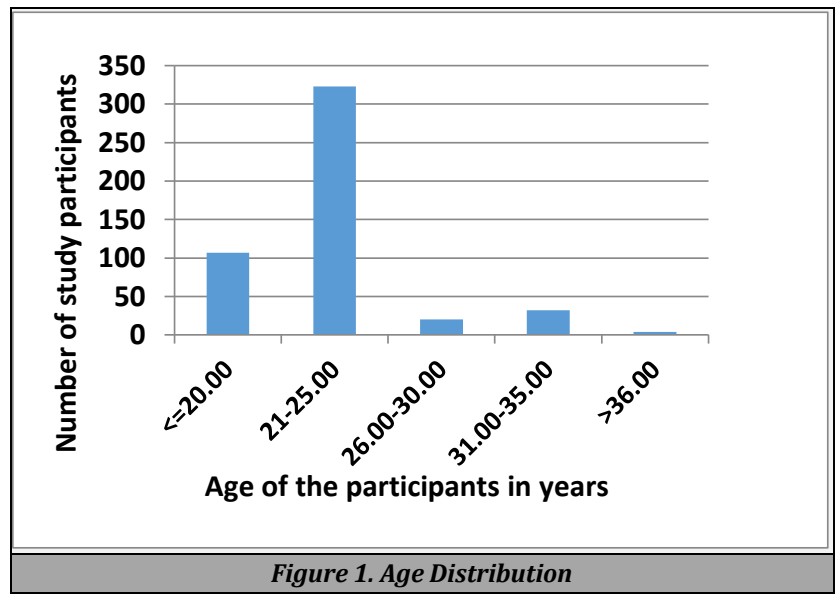

The mean age of the study participants was $24.62+/-3.77$ years. $403(60 \%)$ of the study participants were multigravida while the rest i.e. 204 (40\%) were primigravida. 
A majority 465 (69.4\%) mothers delivered at term i.e. more than 37 weeks, 198 (28.4\%) of them delivered late preterm (32 - 37 weeks) while 15 (2.2\%) delivered in early preterm period ( $<32$ weeks). The mean gestational age was $38.09+/-2.023$ as shown in Table 1 .

\begin{tabular}{|ccc|}
\hline Gestational Age (Weeks) & No of Patients & Percentage \\
$<=32$ & 15 & 2.2 \\
$33-37$ & 190 & 28.4 \\
$>38$ & 465 & 69.4 \\
Total & 670 & 100.0 \\
Mean \pm SD & $38.09 \pm 2.023$ \\
\hline & Table 1. Gestational Age \\
\hline
\end{tabular}

The indications for which CS was conducted is detailed in table 2. The most common indication was previous lower segment caesarean section (LSCS) followed by cephalopelvic disproportion.

\begin{tabular}{|ccc|}
\hline Indications & No. of Patients & Percentage \\
\hline Antepartum haemorrhage (APH) & 13 & 1.9 \\
Cephalopelvic disproportion & 113 & 16.9 \\
Failure to induce & 12 & 1.8 \\
Fetal distress & 92 & 13.7 \\
Hypertensive disorder of pregnancy & 45 & 6.7 \\
Mal presentation & 36 & 5.4 \\
Maternal conditions & 4 & .6 \\
Maternal request & 23 & 3.4 \\
Multiple pregnancy & 12 & 1.8 \\
Non-progress of labour (NPOL) & 29 & 4.3 \\
Poor BISHOP & 6 & .9 \\
Previous LSCS & 222 & 33.1 \\
\hline Severe oligohydramnios & 63 & 9.4 \\
Total & 670 & 100.0 \\
\hline Table 2. Indications of CS among Study Participants \\
\hline
\end{tabular}

Among all CS 179 (26.7 \%) was elective while 491 (73.2\%) were done because of emergency indication as shown in Table 3.

\begin{tabular}{|ccc|}
\hline Mode of Delivery & No. of Patients & Percentage \\
\hline Elective & 179 & 26.7 \\
Emergency & 491 & 73.2 \\
Total & 670 & \\
\hline \multicolumn{3}{|c}{ Table 3. Mode of Delivery } \\
\hline
\end{tabular}

Post-delivery, majority of the babies $78.92 \%$ were stable and present by mother's side, while the rest needed intervention as shown in table 4 . There were 4 twin deliveries, 359 (53.26 \%) babies delivered were males while 315 (46.74 $\%)$ were females.

\begin{tabular}{|ccc|}
\hline Neonatal Outcome & No. of Patients & Percentage \\
Intrauterine device (IUD) & 18 & 2.52 \\
Mothers side & 532 & 78.93 \\
$\begin{array}{c}\text { Neonatal intensive care } \\
\text { unit (NICU) admission }\end{array}$ & 125 & 18.55 \\
Total & 674 & 100 \\
\hline Table 4. Distribution of Neonatal Outcome after Delivery \\
\hline
\end{tabular}

\section{DISCUSSION}

The present study was conducted in a tertiary medical college of North Karnataka to estimate the rates of Caesarean section and evaluate the indications of the same. The study participants in our study were from young age groups. Similarly, study conducted by Aruna Biradar et al. ${ }^{10}$ on primary Caesarean section reported the age group of study participants to be 21 - 30 years. Also study by Benzouina et al. ${ }^{11}$ on CS rates reported mean age of the pregnant women to be 27.8 years. Majority of the mothers in the study were multigravidas which is similar to the finding of Unnikrishnan B et al, $46.8 \%$ cases were primiparous and $47.6 \%$ were multiparous ${ }^{12}$ and also Prasad et al. ${ }^{13}$ and Naeem et al. ${ }^{14}$ In our study only 15 mothers delivered before completing full term. Similarly, Barros et al. ${ }^{15}$ in their study reported that only $10 \%$ of the patients undergoing CS delivered before full term gestation. Also, Leal et al. ${ }^{16}$ reported $38 \%$ preterm birth in patients undergoing CS in public hospitals. The most common cause of CS in our study was previous CS followed by cephalopelvic disproportion.

In a study by Anand Nikhil et al. and Pandya J M et al also reported $42.09 \%$ and $46.2 \%$, respectively as the most common indication for Caesarean section ${ }^{17,18}$ But, in a study by Onankapa et al. ${ }^{19}$ The primary indications for Caesarean section was cephalopelvic disproportion. Also Y. Ali ${ }^{20}$ reported cephalopelvic disproportion (44\%) as the main indication of CS. The observed difference in the indication of CS in our study may be because the obstetricians are scared of giving a trail of labour in cases of previous CS due to medico legal issues.

On the other hand, the contingent rise in repeat Caesarean delivery has been associated with an increase in grievous complications particularly related to that of placentation like placenta previa and placenta accrete which in turn increases the maternal morbidity and even mortality. Foetal distress and hypertensive disorders of pregnancy were the other indication of CS in our study which is similar to a study published by Dinas et al. ${ }^{21}$ and also Similar results were reported in a study by Liu et al. (11.81\%) $)^{22}$ This could be attributed to very liberal use of cardiotocography (CTG) and intense fetal monitoring. A small proportion of CS in our study was due to maternal request which indicates the case of rising operation in whom operations are performed in the absence of medical indication.

This particular trend has been observed in a study conducted in Connecticut, wherein indications exhibiting large annual percentage increases including maternal request. ${ }^{23}$ The operation performed in our study were predominantly due to emergency indication which is similar to the finding of Bukar et al.24 who reported (72.4\%) of the patients had emergency Caesarean delivery. Also, Daniel et al. ${ }^{25}$ reported an emergency CS rate of $57.1 \%$. In our study percentage of patients with hypertensive disorders in pregnancy undergoing emergency CS was $6.7 \%$, similarly a study done by Sangamesh Matapathi et $\mathrm{al}^{26}$ showed $73 \%$ and also a study by Varsha Kosee et al. showed $7.3 \% .{ }^{27}$ In our study male babies were marginally more than the females which was similar to the finding of Dinas et al. ${ }^{21}$ We found $25 \%$ of the new-borns to be having bad neonatal outcome in which is similar to finding of Nakimuli et al. reported high incidence of neonatal mortality on their study. There was no maternal or neonatal mortality noted in our current study.

\section{CONCLUSIONS}

Vaginal delivery is and will always be the better mode of delivery compared to Caesarean section because it has lesser 
morbidity and mortality for both the mother and the newborn. As such, the obstetricians throughout the world must encourage mothers in labour for vaginal delivery as far as possible. Caesarean section due to maternal / foetal indication is inevitable in emergency situations as a rescue procedure. Proper counselling during antenatal period can reduce elective sections done for maternal request. The results indicate high rates of Caesarean section in both urban and rural population. The common indications were previous Caesarean section, cephalopelvic disproportion, hypertensive disorders of pregnancy and request of patient. The increased rate of Caesarean section in multigravida may be due to the changes in physician's perspective of practice in various social and medico-legal issues. Being a tertiary care hospital, a high rate of Caesarean deliveries was observed. Although indication for Caesarean sections were individualised and careful evaluation of the patients was done by following standardized guidelines, but due to multiple and unavoidable factors Caesarean rates are still increasing.

Audit and feedback are the best way to judge clinical practice and to reduce the frequency of Caesarean section in any tertiary setup. Hence, more stringent measures must be adopted to reduce the rate of primary Caesarean section by avoiding the non-medical indication of CS for the interest of wellbeing of the women in both physiological and financial facets.

Data sharing statement provided by the authors is available with the full text of this article at jemds.com.

Financial or other competing interests: None.

Disclosure forms provided by the authors are available with the full text of this article at jemds.com.

\section{REFERENCES}

[1] Appropriate technology for birth. Lancet 1985;2(8452):436-7.

[2] Ye J, Zhang J, Mikolajczyk R, et al. Association between rates of caesarean section and maternal and neonatal mortality in the 21st century: a worldwide populationbased ecological study with longitudinal data. BJOG 2016;123(5):745-53.

[3] FOGSI-Cesarean Rates (JDT). The Federation of Obstetric and Gyneocological Societies of India. https://www.fogsi.org/fogsi-cesarean-rates-jdt/

[4] Betrán AP, Merialdi M, Lauer JA, et al. Rates of caesarean section: analysis of global, regional and national estimates. Paediatr Perinat Epidemiol 2007;21(2):98113.

[5] Ye J, Betrán AP, Vela MG, et al. Searching for the optimal rate of medically necessary cesarean delivery. Birth 2014;41(3):237-44.

[6] Guilmoto CZ, Dumont A. Trends, regional variations and socioeconomic disparities in cesarean births in India, 2010-2016. JAMA Netw Open 2019;2(3):e190526.

[7] Van Roosmalen J, Van Der Does CD. Caesarean birth rates worldwide. A search for determinants. Trop Geogr Med 1995;47(1):19-22.

[8] Hansen AK, Wisborg K, Uldbjerg N, et al. Risk of respiratory morbidity in term infants delivered by elective caesarean section: cohort study. BMJ 2008;336(7635):85-7.

[9] Biradar A, Sajjan GR, Patil N. To evaluate the indications of caesarean section among the population of Karnataka: a prospective cross-sectional study. Journal of Krishna Institute of Medical Sciences University 2019;8(2):63-9.

[10] Benzouina S, El-Mahdi Boubkraoui M, Mrabet M, et al. Fetal outcome in emergency versus elective cesarean sections at Souissi Maternity Hospital, Rabat, Morocco. Pan Afr Med J 2016;23(1):197.

[11] Unnikrishnan B, Prasad RB, Amarnath A, et al. Trends and indications for caesarean section in a tertiary care obstetric hospital in coastal south India. Australasian Medical Journal 2010;3(12):821-5.

[12] Prasad A, Bhandari G, Saha R. Profile of caesarean section at Kathmandu Medical College. J Nepal Health Res Council 2017;15(2):111-3.

[13] Naeem M, Ul Isalam Khan MZ, Abbas SH, et al. Rate and indications of elective and emergency caesarean section; a study in a tertiary care hospital of Peshawar. J Ayub Med Coll Abbottabad 2015;27(1):151-4.

[14] Barros FC, De Lyra Rabello Neto D, Villar J, et al. Caesarean sections and the prevalence of preterm and early-term births in Brazil: secondary analyses of national birth registration. BMJ Open 2018;8(8):e021538.

[15] Do Carmo Leal M, Esteves-Pereira AP, Nakamura-Pereira M, et al. Provider-initiated late preterm births in Brazil: differences between public and private health services. PLoS One 2016;11(5):e0155511.

[16] Nikhil A, Desai A, Vijay K, et al. Analysis of trends in LSCS rate and indications of LSCS- a study in a Medical College Hospital GMERS, Sola, Ahmedabad. International Journal of Pharmacy and Bio-Sciences 2015;2(1):1-5.

[17] Pandya JM, Pandya MJ, Joshi JM, et al. Analytical study of indications of cesarean section. Int J Reprod Contracept Obstet Gynecol 2017;4(5):1460-3.

[18] Onankpa B, Ekele B. Fetal outcome following cesarean section in a university teaching hospital. J Natl Med Assoc 2009;101(6):578-81.

[19] Ali Y. Analysis of caesarean delivery in Jimma Hospital, South-Western Ethiopia. East Afr Med J 1995;72(1):60-3.

[20] Dinas K, Mavromatidis G, Dovas D, et al. Current caesarean delivery rates and indications in a major public hospital in Northern Greece. Aust N Z J Obstet Gynaecol 2008;48(2):142-6.

[21] Nizam K, Haider G, Memon N, et al. Cesarean section rate: much room for reduction. Rawal Med J 2010;35:19-22.

[22] Barber EL, Lundsberg LS, Belanger K, et al. Indications contributing to the increasing cesarean delivery rate. Obstet Gynecol 2011;118(1):29-38.

[23] Bukar M, Audu BM, Massa AA. Caesarean delivery at the Federal Medical Centre Gombe: a 3-year experience. Niger J Med 2009;18(2):179-83.

[24] Daniel CN, Singh S. Caesarean delivery: an experience from a tertiary institution in north western Nigeria. Niger J Clin Pract 2016;19(1):18-24.

[25] Mathapati SS, Biradar AM, Sangolli LS. A study of hypertensive disorders of pregnancy and the fetal outcome in a tertiary care hospital: a prospective stuy. Int J Reprod Contracept Obstet Gynecol 2020;9(8):1-4.

[26] Kose V, Sadhvi K. Study of caesarean section at tertiary care centre: a retrospective study. International Journal of 
Reproduction, Contraception, Obstetrics and Gynecology 2020;9(5):2139.

[27] Nakimuli A, Nakubulwa S, Kakaire O, et al. Incidence and determinants of neonatal morbidity after elective caesarean section at the national referral hospital in Kampala, Uganda. BMC Res Notes 2015;8(1):624. 